\title{
Savings associated with high-dose hypoallergenic house dust mite immunotherapy in rhinitis and/or asthma patients in Spain
}

This article was published in the following Dove Press journal:

ClinicoEconomics and Outcomes Research

14 June 2016

Number of times this article has been viewed

\author{
José Carlos García Robaina' \\ Carlos Polanco Sánchez ${ }^{2}$ \\ Elvira Estella Pérez ${ }^{2}$ \\ 'Allergy Department, University \\ Hospital Nuestra Señora de \\ Candelaria, Santa Cruz de Tenerife, \\ ${ }^{2}$ Health Economics \& Outcomes \\ Research, Corporate Affairs, Merck \\ S.L., Madrid, Spain
}

Objectives: To quantify the cost difference between conventional symptomatic treatment of mite allergy and specific subcutaneous immunotherapy (SCIT).

Methods: Observational, retrospective, and multicenter study was carried out in Spain in 2013. The medical records of 419 patients diagnosed with rhinitis and/or bronchial asthma for mite allergy were retrieved. Mean age was 24.9 years (standard deviation 14.4). The use of symptomatic medication (rescue and daily), diagnostic tests, unscheduled medical care, and sick leave days associated with SCIT treatment versus no-SCIT treatment was compared. Also measured was the SCIT treatment to no-SCIT treatment costs ratio: used resources (symptomatic medication, unscheduled medical care, diagnostic tests, and 3 years SCIT treatment and sick leave days) were quantified in euros. Efficacy (decreased resource usage) of first-year treatment was assumed during the remaining 2 years and also during the 3-year follow-up period.

Results: After a single year of SCIT, all quantified resources diminished significantly $(P<0.05)$ from baseline. Estimated reduction in cost items included hospital resources (100\% in hospitalizations, $82 \%$ in visits to the allergist, and $79 \%$ in emergency room visits), therapies (56\% in rescue medication and $63 \%$ in daily medication), diagnostic tests (77\%), and sick leave days (94\%). Ratio of comparative calculation described as SCIT treatment versus non-SCIT treatment (or conventional symptomatic treatment) is 0.8 .

Conclusion: Direct costs are reduced by $64 \%$ and indirect costs by $94 \%$. SCIT of hypoallergenic preparation of dust mite $\left(\right.$ Acaroid $^{\circledR}$ ) allows cost savings versus conventional treatment. Estimated savings for the public National Health System are 5.7 times the cost of immunotherapy. Keywords: asthma, economic evaluation, immunotherapy, rhinitis.

\section{Introduction}

Advances in medicine in recent years have provided better quality of life for the population; however, these new technologies also involve a higher cost of therapy and ultimately more health spending. Therefore, tools are necessary to ensure that the adoption of these new technologies in the National Health System (NHS) does not occur indiscriminately but in a sustainable manner. ${ }^{1}$

To ensure the sustainability of the NHS, Spain has begun to include economic evaluations of health technologies that provide evidence of the economic value that these new technologies bring. ${ }^{1}$

In addition, the incidence and prevalence of allergic respiratory diseases mediated by immunoglobulin $\mathrm{E}$, such as allergic rhinitis and asthma, have increased markedly in recent decades both in Western and developing countries. ${ }^{2,3}$ 
The presence of allergic diseases such as allergic rhinitis or asthma significantly increases the use of health resources and services. ${ }^{4,5}$ House dust mites are one of the most common airborne allergens worldwide, with great capacity to cause sensitization. Their involvement in rhinitis, asthma, or other allergic diseases is widely known.

Specific immunotherapy (IT) has the potential to alter the course of allergic disease, thus reducing the need for long-term treatment and the risk of progression of allergic disease $^{6,7}$ or the development of new sensitizations, ${ }^{4,5}$ in contrast to symptomatic treatment.

International studies suggest that IT compared to drug therapy is cost-effective for patients with rhinoconjunctivitis and/or asthma. Other studies also show that treatment with additional specific subcutaneous immunotherapy (SCIT) brings better health outcomes and associated cost savings compared to symptomatic treatment alone. ${ }^{8}$

A piggy-back study involving 65 children and adolescents with allergic asthma to mites who were receiving treatment for 3 years based on a hypoallergenic high-dose preparation concluded that due to the reduction in drug use, a decline occurred in the costs from the first year and the additional costs associated with SCIT were offset by savings in drugs for symptomatic treatment 4 years after the end of SCIT. ${ }^{9}$

\section{Objective}

The aim of this study is to quantify the long-term savings between specific SCIT treatment consisting of high-dose house dust mite extract (Acaroid ${ }^{\circledR}$, Merck - Allergopharma Joachim Ganzer KG, Reinbek, Germany) for 3 years combined with conventional symptomatic treatment (oral antihistamines, bronchodilators, eye drops, and corticosteroids). The savings estimate is based on comparing the cost of said treatment with that associated with the conventional use of only symptomatic treatment for 6 years.

\section{Patients and methods Description of the study}

Observational, retrospective, and multicenter study was carried out in Spain in 2013 in $(\mathrm{n}=419)^{10,11}$ adult patients (aged 18 or older) with a mean age of 24.9 years (standard deviation $14.4)$ in both sexes $(52.5 \%, 220$ female) diagnosed with rhinitis and/or bronchial asthma for mite allergy, who had received said immunotherapy treatment (ITT) in the previous year.

The ITT was performed as indicated in Acaroid ${ }^{\circledR}$ summary of product characteristics: the treatment began with administration of the lowest product concentration once a week, increasing the dose every week until reaching the individual tolerability limit. From that moment onwards began the follow-up treatment, consisting of administration of the reached dose every 4 weeks.

The sample for the different variables included all subjects meeting the selection criteria, who showed no major protocol deviations and had completed at least 9 months of treatment from the administration of the first maintenance dose. The study was approved by the Ethics Committee at the Hospital Puerta del Mar in Cádiz, Spain on March 13, 2013 and classified by the Spanish Medicines Agency. Written informed consent was obtained from patients or legal guardians.

\section{Statistical analysis}

The data analysis was performed using the Statistical Package SAS System for Windows (SAS Institute Inc., Cary, NC, USA). In all statistical tests with outcome variables, a level of 0.05 was considered significant except for preliminary tests of normality or homogeneity of variance, for which a significance of 0.1 was used. Friedman's test was performed to compare the evolution over time of symptoms and medication (scheduled and used) after 1 year from the start of the treatment. An economic model was created that extrapolated to 6 years the results of the study during the first year of IT assuming 3 years of active treatment (according to the usual pattern recommended by the manufacturer) and 3 years of follow-up.

The results regarding the evolution of unscheduled health care $(P<0.05)$ and rescue medication $(P<0.05)$ were published in the REME study (Table 1). ${ }^{12}$

\section{Cost variables}

To calculate the associated cost difference between the two options, unscheduled medical care, medication use, and days off work were quantified by reference to the data available in the patient's history regarding the previous month at the initiation of IT and later in the month prior to completing the corresponding case report form (CRF) data.

The patients were subjected to monitoring and observation of symptoms and their intensity before taking the decision to establish treatment with IT and during its evolution.

Later, the charges associated with the decline of these quantified resources (direct actions) were calculated. Not quantified in the study, due to not to being covered by the CRF, were all the patient's visits to primary care before being referred to an allergist.

Finally, an economic model was built that extrapolated to 6 years retrospective study results obtained after 1 year of treatment. This model assumed 3 years of active treatment with IT 
Table I Evolution of unscheduled medical care and rescue medication

\begin{tabular}{|c|c|c|c|c|}
\hline Cost item & Pretreatment & Posttreatment & $\%$ & $P$-value \\
\hline Number of urgent care visits & 124 & 26 & -79.06 & $<0.0001$ \\
\hline Number of days in hospital & 9 & 0 & -100.00 & 0.0253 \\
\hline Number of additional diagnostic tests* & 183 & 49 & -73.22 & $<0.0001$ \\
\hline Number of allergist visits & 91 & 16 & -82.42 & $<0.0001$ \\
\hline Number of additional diagnostic tests** & 83 & 16 & -80.72 & $<0.0001$ \\
\hline Number of days off & 194 & 12 & -93.81 & $<0.0001$ \\
\hline Oral antihistamine as needed, $\mathrm{n}(\%)$ & $27 \mid(64.7 \%)$ & $244(60.8 \%)$ & -6.00 & 0.0487 \\
\hline Bronchodilator as needed, $\mathrm{n}(\%)$ & $160(38.2 \%)$ & $122(30.4 \%)$ & -20.00 & $<0.0001$ \\
\hline Eye drops as needed, $\mathrm{n}(\%)$ & 48 (II.5\%) & $21(5.2 \%)$ & -54.70 & $<0.0001$ \\
\hline Nasal corticosteroid as needed, n (\%) & $173(41.3 \%)$ & $107(26.7 \%)$ & -35.30 & $<0.0001$ \\
\hline
\end{tabular}

Notes: *Hospital diagnostic tests. **Diagnostic tests in allergy department. Data from El-Qutob et al. ${ }^{12}$

and three subsequent years of monitoring. A comparative calculation was made - pre- and post-ITT - of the following costs:

- Direct health costs: These included costs associated with hospitalization, emergency room visits, visits to specialized care, unscheduled medical care, diagnostic tests, use of rescue/scheduled medication, and IT (only ITT option).

- Indirect costs: These included costs related to absenteeism or loss of productive capacity, counting only the days of sick leave recorded by patients as the only variable of this type recorded in the study.

The costs were calculated for the total of patients in the basal measurement. Direct health care costs were quantified for all patients by multiplying the natural units of health resources used (from the retrospective study) with the unit cost of each, using for this the official price rates of resources (Table 2). ${ }^{13}$

The direct health care costs related to the consumption of rescue and scheduled therapy were obtained after quantifying each unit (drop, tablet, or inhalation) of medication (eye drops, oral antihistamine, bronchodilator, or corticosteroid) reported in the retrospective study.

The reported dose set was grouped into packages for the entire group and quantified at cost Public Price, for which BOTplusWEB (Consejo General de Colegios Oficiales de Farmacéuticos, Madrid, Spain) was used. ${ }^{14}$

Finally, the average daily expenditure (scheduled daily medication) and weekly expenditure per patient ("as needed" medication) used in the extrapolation were calculated.

Indirect costs included only the costs associated with lost working hours due to sick leave. The cost of a day off work was calculated as the average cost of an hour worked, published in a Spanish study of the cost of asthma. ${ }^{15}$

The ITT option reflected the cost of 3 years of the stipulated treatment. This plan of treatment required a starter pack of vial A + vial B, two vials of B, and an additional vial of
Table 2 Unit costs used in the model

\begin{tabular}{|c|c|c|c|}
\hline Item & Cost $(€)$ & Item & Cost $(€)$ \\
\hline Visits to urgent care ${ }^{18}$ & 221.08 & $\begin{array}{l}\text { Spirometry + } \\
\text { BD tests }{ }^{19}\end{array}$ & 125.12 \\
\hline Hospital admission ${ }^{18}$ & 649.92 & $\begin{array}{l}\text { Pretreatment } \\
\text { daily medication }{ }^{14}\end{array}$ & 2.93 \\
\hline Successive visits (to allergist) ${ }^{18}$ & 79.90 & $\begin{array}{l}\text { Pretreatment } \\
\text { weekly medication } \\
\text { as needed }{ }^{14}\end{array}$ & 3.61 \\
\hline Measuring FeNO & 39.00 & $\begin{array}{l}\text { Post-treatment } \\
\text { daily medication }{ }^{14}\end{array}$ & 0.31 \\
\hline Chest X-ray ${ }^{18}$ & 149.74 & $\begin{array}{l}\text { Post-treatment } \\
\text { weekly medication } \\
\text { as needed }{ }^{14}\end{array}$ & 0.97 \\
\hline \multicolumn{3}{|l|}{ Cost of I hour of daily work ${ }^{15}$} & 7.36 \\
\hline \multicolumn{3}{|c|}{ Cost of primary care visit without additional tests ${ }^{18}$} & 39.00 \\
\hline
\end{tabular}

Abbreviation: BD, bronchodilator.

B. Its cost was quantified as Public Price. To this cost was added an amount representing the cost of applying each dose.

\section{Sensitivity analysis}

All pharmacoeconomic analyses should include a sensitivity analysis to assess the impact of each variable on the estimated results. ${ }^{16}$ To this end, a sensitivity analysis was performed, represented through a tornado diagram of the variation in estimated savings to variations of $\pm 25 \%$ in the various cost items.

The cost items considered in this case were daily medication, as-needed medication, emergency room visits, established salary/hour, spirometry + bronchodilation tests, additional allergist visits, hospitalization, chest X-ray, spirometry, FeNO measurement test, and $\mathrm{O}_{2}$ saturation test.

This study considered a large number of variants, and therefore, the tornado diagram was considered appropriate to represent the results of the sensitivity analysis, and consequently, all the univariate analyses of each variable were summarized in a single diagram. 


\section{Results}

The retrospective study showed that after a year of IT, a statistically significant decrease from baseline occurred in all the resources quantified: need for unscheduled medical care, urgent care visits and specialist diagnostic tests, medication, and days off work $(P<0.05)$.

After a year of treatment, the need for unscheduled medical assistance decreased from the months before commencement. While in these months $16.3 \%$ of patients required urgent care, $14.6 \%$ saw an allergist, and $7.7 \%$ missed work or school; after a year of treatment, these percentages dropped to $4.5 \%, 3.7 \%$, and $1.2 \%$, respectively. As for scheduled medication for daily use, at baseline, $85.4 \%$ of patients had at least one drug scheduled for daily use and after a year, this figure was $52.1 \%$. There was also a significant decrease in the use of rescue medication compared to its use in the months before the start of the treatment.

After the monetary quantification of the above resources used in both scenarios, there was a decrease of $64 \%$ in direct health care costs (unscheduled medical care, tests, and medication), excluding those related to IT and 94\% in indirect costs considered in the model (days of sick leave).

Following the completion of the economic model, savings were estimated per patient at 6 years, comparing costs
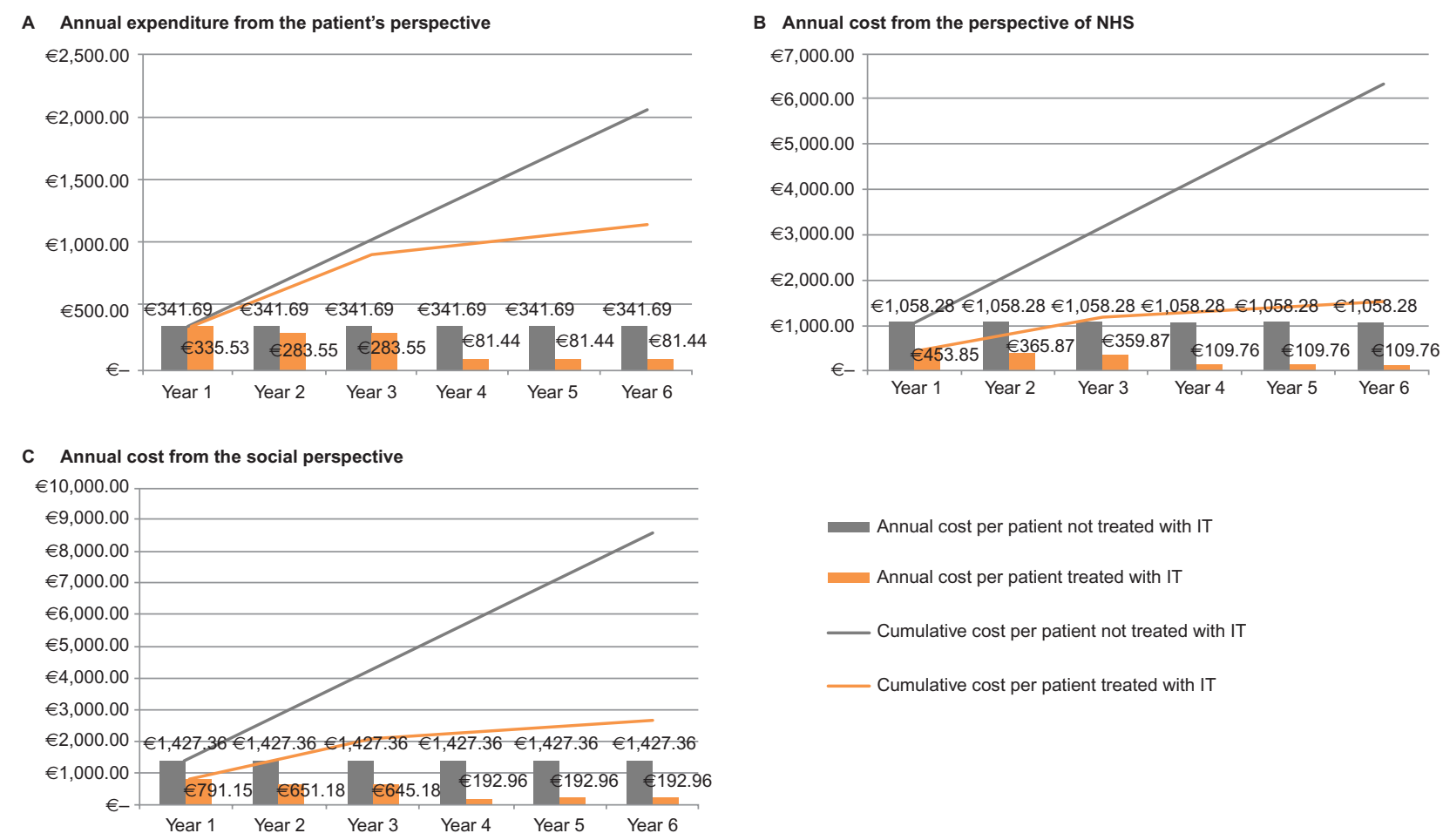

\section{Sensitivity analysis}

Sensitivity analysis is represented by the tornado diagram (Figure 2), which shows the fluctuation in estimated savings by considering the variations in cost of items. While the most influential variable was "daily medication", in all simulated cases, there were estimated savings associated with the use of IT.

Univariate sensitivity analysis was performed to determine which variables (excluding the price of IT) could influence modeling in a major way, resulting in "as needed medication" and "daily medication" as the variables that had the most impact on the outcome. For inclusion of these variables in the model, they were monetarily quantified (cost per $\mathrm{mL}$, tablet, puff, and inhaling) based on the amount of antihistamines, eye drops, bronchodilators, and corticosteroids strictly provided and reported in the CRF, but without considering the purchase in a box or a container, or its expiration. For this reason, there is an underestimation of

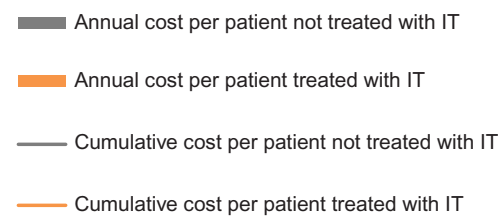

Figure I Annual expenditure from the different perspectives considered.

Notes: (A) Annual expenditure from the patient's perspective. (B) Annual cost from the perspective of NHS. (C) Annual cost from the social perspective. Abbreviations: IT, immunotherapy; NHS, National Healthcare System. 


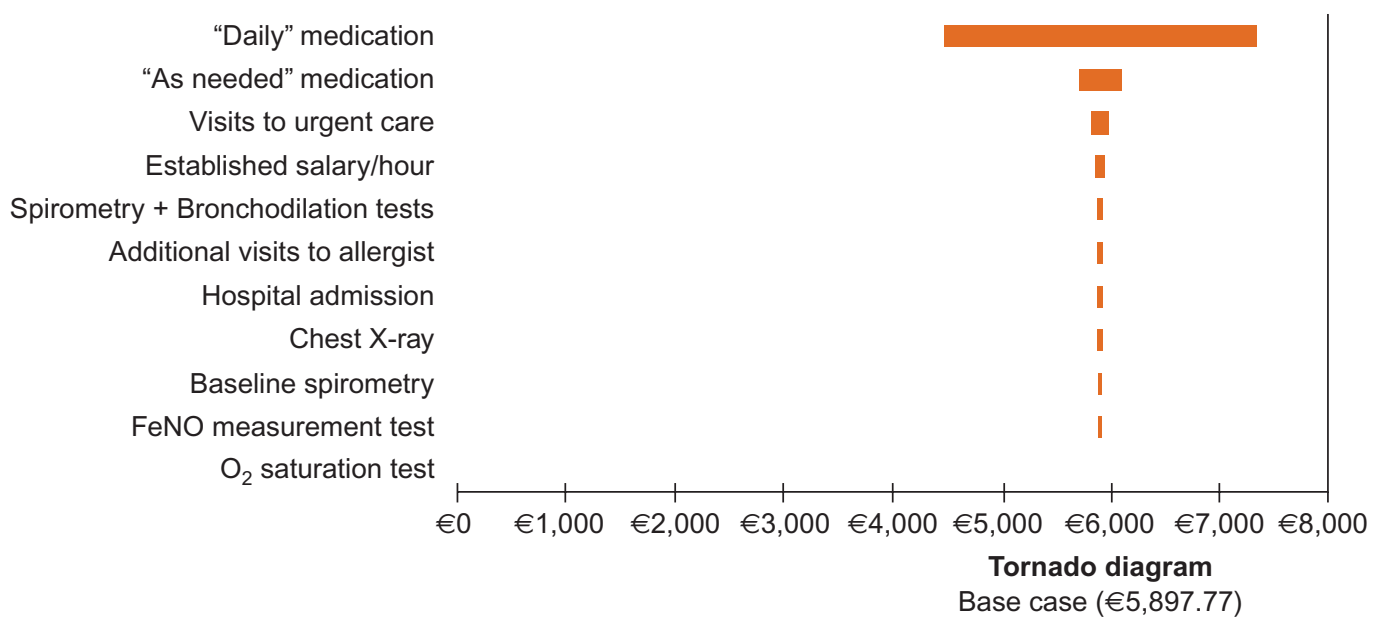

Figure 2 Sensitivity analysis.

the savings associated with the two high-impact variables in the model, which were estimated conservatively. Increasing the cost of these variables by $25 \%$ from a weekly cost of treatment medication before/after treatment $-€ 6.78 / € 2.79$ to $€ 8.49 / € 3.52$ - yielded a base case savings of €792.15.

\section{Discussion}

According to the model, 3 years after discontinuation of a 3-year course in IT, the estimated savings per patient treated with Acaroid ${ }^{\circledR}$ were $€ 903.18$ for the patient, $€ 4,840.80$ for the NHS, and $€ 5,897.77$ from a social perspective. As shown in Table 3, the ratio of costs to the patient treated with IT versus untreated patients with IT is 0.56 ; that is, the cost borne by the patient treated with IT is almost half the cost borne by the patient untreated with IT. However, this ratio is even more pronounced for the NHS, in which the costs generated by the patients not treated with IT are more than four times greater than the costs of patients treated with IT.

The main limitation of this analysis is, perhaps, the extrapolation of the results to 6 years (and their associated costs) obtained after the first year in the retrospective study, and possible biases with this design, although this approach has been used in other works. ${ }^{17}$ This extrapolation may have led to an underestimation of the savings associated with ITT because the model does not take into account the cumulative real potential over time of IT in patient improvement, and therefore, in reducing the use of health resources (eg, those associated with lower rates of asthma and other disorders).

Therefore, extrapolating the results of the first year may yield a less accurate estimate of savings because of the following:

1. Considering in the 3 years following the completion of ITT the same costs as in the first year.
Table 3 Savings and ratios from different perspectives

\begin{tabular}{llll}
\hline & Patient & NHS & Social \\
\hline $\begin{array}{l}\text { Savings per patient over } \\
6 \text { years }(€)\end{array}$ & 903.18 & $4,840.80$ & $5,897.77$ \\
$\begin{array}{l}\text { Average annual savings } \\
\text { per patient }(€)\end{array}$ & 150.53 & 806.80 & 982.96 \\
$\begin{array}{l}\text { Ratio of treated with IT to } \\
\text { untreated with IT }\end{array}$ & 0.56 & 0.24 & 0.31 \\
\hline
\end{tabular}

Abbreviations: IT, immunotherapy; NHS, National Healthcare System.

2. Not considering that a percentage of untreated patients with the same illness could worsen and thus cause an increase in health care costs and indirect costs.

3. Costs prior to referral to allergist from primary care because they are not recorded in the CRF.

4. The medication consumption is based on what the patient recalled and reported to the investigators. The extrapolation model does not include nonadherence that may arise in subsequent years.

The actual costs of the tests and services may be different - eg, allergist visits - from those used in the model, as rates vary between autonomous communities, although as shown in the sensitivity analysis, these variables exert a resounding impact on the model, as does daily medication (the costs of which are the same nationally).

Another weakness of the model would be the noninclusion of direct nonmedical costs (those associated with trips to the allergist, hospital, urgent care, and so on); it is important to perform this analysis from a social perspective and not only from the perspective of the NHS. Moreover, not considering additional indirect costs (loss of production of goods and services caused by a disease) besides those associated with the days of sick leave recorded in the CRF and quantified based on minimum salary/hour yields 
a less accurate estimate of the overall savings generated by establishing a simplistic assumption to determine the loss of production of goods and services, given the data collected in the CRF.

\section{Conclusion}

This is the first study on the cost efficiency of IT. Although this study requires prospective validation, it is concluded that SCIT with allergoid of high doses of major mite allergens (Acaroid $^{\circledR}$ ) not only involves significant improvements in the quality of life perceived by the patient and doctors but also allows cost savings over conventional therapy, thus promoting the sustainability of the NHS.

This model under conservative assumptions and a horizon of 3 years of active treatment and 3 years of monitoring concludes that when the cost (number of packs) of both IT and medication is counted and official rates of autonomous communities are considered, the following estimated savings result: $€ 903.18$ for the patient, $€ 4,840.80$ for the NHS, and $€ 5,897.77$ from a social perspective. These estimates result in net savings for the NHS that are 5.7 times higher than the assumed cost of high-dose SCIT of major mite allergen.

The results of this study document that specific IT, beyond producing clinically significant improvements in allergic reactions can in the long run allow less use of resources.

This article can improve the knowledge of the distribution of health resources used in the management of allergy, as an aid in making decisions that allow more efficient use of such resources.

\section{Acknowledgments}

We wish to thank all the investigators who have participated in this study: Dr M Pérez Estrada (Málaga), Dr A Miranda Paez (Hospital Civil de Málaga), Dra ML Castellón Miranda (Hospital Comarcal de Melilla), Dr Ignacio García Núñez (Málaga), Dra Majosé Gimenez Romero (Málaga), Dra T Garriga (Barcelona), Elena Botey (Barcelona), Dra Sonia Gelis (Barcelona), Dr Ruperto González (Hospital del Torax, Sta. Cruz de Tenerife), Dra Poza Guedes (Hospital del Torax, Sta. Cruz de Tenerife), Dr García Robaina (Hospital Universitario Nuestra Señora de la Candelaria, Sta. Cruz de Tenerife), Dra E Rodríguez Plata (Hospital Universitario Nuestra Señora de la Candelaria, Sta. Cruz de Tenerife), Dra Guacimara Hernández (Hospital Universitario Nuestra Señora de la Candelaria, Sta. Cruz de Tenerife), Dr Víctor
Matheu (Hospital del Torax, Sta. Cruz de Tenerife), Dr Javier Iglesias (Hospital del Torax, Sta. Cruz de Tenerife), Dr Gustavo Egües (CAP Ramón Vinyes, Girona), Dra Adriana Izquierdo (Barcelona), Dr Enrique Martín Casañez (Hospital General Villarrobledo, Albacete), Dr R Rodríguez Pacheco (Hospital Gral. De Elda, Alicante), Dr E Funes Vera (Hosp. D. Rafael Mendez, Murcia), Dr J Domenech (Hospital Gral. De Elda, Alicante), Dra Purificación González (Hospital Gral. Universitario de Alicante), Dra Sara Díaz Angulo (Oviedo), Dr Javier Carballada Glez (Lugo), Dr JA Álvarez Fernández (Oviedo), Dr FJ Muñoz Bellido (Hosp. Virgen de la Vega, Salamanca), Dra M Torres Gorriz (Valencia), Dr David El Qutob (Hospital de La Plana, Castellón), Dra Alvariño Martín (Hosp. De Manises), Dra P Alba Jorda (Hosp. de Manises), Dr F Matoses Vendrel (Hosp. Gral. Univ. Valencia), Dra Man San Miguel (Hosp. Del Vendrell, Tarragona), and Dr JR Lavín (Barcelona), and nurses who worked with them.

\section{Disclosure}

Carlos Polanco Sánchez and Elvira Estella Pérez are full-time employees of Merck S.L., Spain. This study was sponsored by Merck, SL. The authors report no other conflicts of interest in this work.

\section{References}

1. López Bastida J, Oliva J, Antoñanzas F, et al. Propuesta de guía para la evaluación económica aplicada a las tecnologías sanitarias [Guidelines proposal for the economic evaluation applied to health technologies]. Gac Sanit. 2010;24(2):154-170. Spanish.

2. Eder W, Ege MJ, Von Mutius E. The asthma epidemic. N Engl J Med. 2006;355(21):2226-2235.

3. Ait-Khaled N, Odhiambo J, Pearce N, et al. Prevalence of symptoms of asthma, rhinitis and eczema in 13- to 14-year-old children in Africa: The International Study of Asthma and Allergies in Childhood Phase III. Allergy. 2007;62(3):247-258.

4. Halpern MT, Schmier JK, Richner R, Guo C, Togias A. Allergic rhinitis: a potential cause of increased asthma medication use, costs, and morbidity. J Asthma. 2004;41(1):117-126.

5. Thomas M, Kocevar VS, Zhang Q, Yin DD, Price D. Asthma-related health care resource use among asthmatic children with and without concomitant allergic rhinitis. Pediatrics. 2005;115(1):129-134.

6. Leger D, Annesi-Maesano I, Carat F, et al. Allergic rhinitis and its consequences on quality of sleep: an unexplored area. Arch Intern Med. 2006;166(16):1744-1748.

7. Stewart MG. Identification and management of undiagnosed and undertreated allergic rhinitis in adults and children. Clin Exp Allergy. 2008;38(5):751-760.

8. Brüggenjürgen $\mathrm{B}$, Reinhold $\mathrm{T}$, Brehler R, et al. Cost-effectiveness of specific subcutaneous immunotherapy in patients with allergic rhinitis and allergic asthma. Ann Allergy Asthma Immunol. 2008;101:316-324.

9. Reinhold T, Ostermann J, Thum-Oltmer S, Brüggenjürgen B. Influence of subcutaneous specific immunotherapy on drug costs in children suffering from allergic asthma. Clin Transl Allergy. 2013;3:30. 
10. Efectividad a corto plazo y mejora de la calidad de vida con un extracto subcutáneo modificado de altas dosis de ácaros [Short term effectiveness and quality of life improvement with subcutaneous high-dose dust mite extract]. XXIX SEAIC Congress Poster 77. Spanish.

11. Efectividad a corto plazo y mejora de la calidad de vida de pacientes pediátricos con un extracto subcutáneo modificado de altas dosis de ácaros [Short term effectiveness and quality of life improvement of pediatric patients with subcutaneous high-dose dust mite extract]. XXIX SEAIC Congress Poster 322. Spanish.

12. El-Qutob D, Moreno F, Subtil-Rodriguez A. Specific immunotherapy for rhinitis and asthma with a subcutaneous hypoallergenic high-dose nouse dust mite extract: results of a 9-month therapy. Immunotherapy. Epub 2016, May 18.

13. comb.cat [homepage on the Internet]. Catalogue of names. Physicians Association; 2016 [updated 2016; cited march, 2016] Available from: https://www.comb.cat/cat/professional/asselliure/nomenclator.html. Accessed March 1, 2016.

14. botplusweb.portalfarma.com [homepage on the Internet]. General Council of the Official College of Pharmacists; 2016 [Updated 2016; cited March, 2016]. Available from: https://botplusweb.portalfarma. com/. Accessed March 1, 2016.
15. Martínez-Moragón E, Serra-Batllés J, De Diego A, et al. Coste económico del paciente asmático en España [Economic cost of asthma patient in Spain] (studio AsmaCost). Arch Bronconeumol. 2009;45(10):481-486. Spanish.

16. Bastida JL, Oliva J, Antoñanzas F, et al. Propuesta de guía para la evaluación económica aplicada a las tecnologías sanitarias [Economic evaluation guidelines proposal applied to health technologies]. Gac Sanit. 2010;24(2):154-170. Spanish.

17. Keiding H, Jorgensen KP. A cost-effectiveness analysis of immunotherapy with SQ allergen extract for patients with seasonal allergic rhinoconjunctivitis in selected European countries. Curr Med Res Opin. 2007;23(5):1113-1120.

18. gobiernodecanarias.org [homepage on the Internet]. Public Prices of health benefits. Health Service of Canarias. 2014 [updated February 1, 2014; cited March 1, 2016]. Available from: http://www.gobiernodecanarias.org/boc/2014/061/001.html. Accessed March 1, 2016.

19. osakidetza.euskadi.eus [homepage on the Internet]. Teaching and health service billing rates of Osakidetza. Health Service of the Basque Country; 2014 [updated January 1, 2014; cited March 1, 2016]. Available from: http://www.osakidetza.euskadi.eus/r85-ckproc05/es/contenidos/ informacion/libro_tarifas/es_libro/adjuntos/tarifas2014.pdf. Accessed March 1, 2016.

\section{ClinicoEconomics and Outcomes Research}

\section{Publish your work in this journal}

ClinicoEconomics and Outcomes Research is an international, peerreviewed open-access journal focusing on health technology assessment, pharmacoeconomics and outcomes research in the areas of diagnosis, medical devices, and clinical, surgical and pharmacological intervention. The economic impact of health policy and health systems
Submit your manuscript here: https://www.dovepress.com/clinicoeconomics-and-outcomes-research-journal

\section{Dovepress}

organization also constitute important areas of coverage. The manuscript management system is completely online and includes a very quick and fair peer-review system, which is all easy to use. Visit http://www.dovepress.com/testimonials.php to read real quotes from published authors. 